\title{
1 Surface Tunable Magnetic Nano-sorbents for Carbon Dioxide Sorption and Separation
}

15 *To whom correspondence should be addressed:

16 John D. Fortner: Tel: +1-314-935-9293; Fax: +1-314-935-5464; Email: jfortner@ wustl.edu 


\section{KEYWORDS}

18 Magnetite nanoparticles, Polyethylenimine, Nanocomposite, $\mathrm{CO}_{2}$ capture 


\section{ABSTRACT}

20 The increasing level of carbon dioxide $\left(\mathrm{CO}_{2}\right)$ in the atmosphere is directly linked to global

21 climate change, which has motivated a number of technological-based mitigation approaches for

22 carbon capture and storage. Among these, $\mathrm{CO}_{2}$ sorption using solid sorbents is one of the most

23 promising strategies. This report focuses on the development and evaluation of novel, hybrid

24 inorganic-organic magnetic nano-sorbents for advanced, high capacity $\mathrm{CO}_{2}$ sorption and

25 magnetic separation processes. Magnetic nanocomposites were prepared by grafting various

26 polymers (e.g. polyethylenimine, polyethylene glycol, etc.) onto magnetite nanoparticles

27 (nMAG) through solution-based sonication and evaporation methodologies. Further, we

28 demonstrate that nMAG can be coated with polyethylenimine (PEI) with different molecular

29 weights (Mw) and structures (linear vs. branched), yielding nMAG nanocomposite libraries with

30 varied PEI loadings and combinations of amine types (primary, secondary, and tertiary amines).

31 Surface functionalized nMAG nanocomposites were characterized by TEM, BET, SQUID, and

32 FTIR techniques and evaluated for $\mathrm{CO}_{2}$ adsorption capacity and recyclability with TGA. Among

33 the as-prepared materials, PEI-nMAG shows the highest $\mathrm{CO}_{2}$ adsorption capacity with superior

34 selectivity and recyclability. 


\section{INTRODUCTION}

36 Carbon dioxide $\left(\mathrm{CO}_{2}\right)$ is a primary greenhouse gas with anthropogenic sources significantly

37 contributing to global increasing atmospheric levels, which are now above $400 \mathrm{ppm}-\mathrm{a} 40 \%$

38 increase compared to the ca. $280 \mathrm{ppm}$ level before industrial revolution.[1-6] Further, driven by

39 continued demand for fossil fuel energy, it is likely that atmospheric $\mathrm{CO}_{2}$ concentrations will

40 further increase.[1-4] To address this global issue, a wide range of technological options has

41 been explored. Among these, carbon capture and storage (CCS) from large point sources (e.g.

42 fossil fuel based power plants) has attracted broad consideration and attention from government,

43 industry, and academia.[7-12] $\mathrm{CCS}$ consists of $\mathrm{CO}_{2}$ capture and separation followed by

44 compression, transport, and permanent storage in deep oceans and geological reservoirs either in

45 the form of supercritical liquid or solidified carbonates.[5, 11, 13, 14] Given the relative larger

46 energy consumption for $\mathrm{CO}_{2}$ capture and separation compared to the transport and storage of

$47 \mathrm{CO}_{2}$, extensive research has been focused on developing new approaches to reduce the cost for

$48 \mathrm{CO}_{2}$ sorption and separation.[2, 13, 15, 16] Adsorption / absorption with solid / liquid sorbents,

49 cryogenic distillation methods, biological fixation as well as membrane separation have been the

50 most commonly studied CCS techniques for gas mixtures.[5, 17-21] Within the spectrum of CCS

51 technologies, $\mathrm{CO}_{2}$ adsorption using solid sorbents is considered to be a promising technique

52 compared to typical aqueous (amine-based) sorbents (i.e. monoethanolamine, MEA) due to low

53 energy requirements, high thermal stability, and ease of regeneration for post-combustion /

54 recycling processing.[2, 22-24] Numerous solid sorbents have been investigated for $\mathrm{CO}_{2}$ capture,

55 including activated carbon, mesoporous silica, zeolites, molecular sieves, metal organic

56 frameworks (MOF), graphene/graphene oxide, and metal oxides, among others.[5, 8, 10, 14, 16,

57 18, 25, 26] More recently, sorption technologies incorporating surface functionalized engineered 
nanomaterials have demonstrated superior physical and chemical properties compared to

59 traditional sorbent strategies, due to their large surface area, and tunable core / surface

60 chemistries, offering unique advantages including low pressure capture, high temperature

61 operation, and superior selectivity.[15, 19, 21, 25, 27, 28]

62 Single crystal magnetite $\left(\mathrm{Fe}_{3} \mathrm{O}_{4}\right)$ nanoparticles have the ability to respond to an external

63 magnetic field, allowing for potentially simple placement/recovery, thus lower separation energy

64 and material input requirements.[29] Further, magnetite is abundant and relatively stable in the

65 environment.[6] Due to low cost and high biocompatibility (i.e. relatively low toxicity),

66 magnetite based (nano)materials have been widely used in fields of biomedical research, physics,

67 data storage, catalyst, and environmental engineering.[29-31] Magnetic-based nanocomposites

68 have also been developed and evaluated for their sorption performance toward $\mathrm{CO}_{2}$ capture. By

69 decorating commercial carbon black with magnetite nanoparticles, Alfe et al. demonstrated a

70 cost-effective method to synthesize magnetic sorbents with high $\mathrm{CO}_{2}$ uptake capacities and good

71 regeneration properties.[24] Mishra et al. have systematically investigated the performance of

72 magnetic carbon materials functionalized with $\mathrm{Fe}_{3} \mathrm{O}_{4}$ nanoparticles, such as multi walled carbon

73 nanotubes (MWNTs), graphene, and graphite nanoplatelets.[3, 11, 26] Under high pressure, each

74 of the magnetic nanocomposites demonstrated a large enhancement in $\mathrm{CO}_{2}$ adsorption capacity,

75 resulting from sorption processes to both the functional groups (from the carbon substrates) and

76 the iron oxide nanoparticles. Recently, Liu et al. reported the functionalization of magnetic $\mathrm{Fe}_{3} \mathrm{O}_{4}$

77 nanoparticles prepared from co-precipitation methods with PEI through solution-based reaction

78 pathways.[29] The material exhibits high $\mathrm{CO}_{2}$ sorption capacity of $0.373 \mathrm{~mol} / \mathrm{L}$, albeit system

79 performance was only tested at $40{ }^{\circ} \mathrm{C}$ and in the aqueous phase. The functionalization or

80 incorporation of magnetite with either amine containing polymers or carbon-based materials can 
81 greatly improve the $\mathrm{CO}_{2}$ adsorption capacity.[1] For these, the higher sorption capacities are

82 mainly due to the large surface area and specific interaction between $\mathrm{CO}_{2}$ and amine-based

83 functional groups.[1, 32] These types of magnetic sorbents offer several advantages, including

84 high sorption capacity, low capital cost, and easy separation compared to traditional aqueous

85 amine solvents.[29] For industrial application, solid amine-based sorbents are usually evaluated

86 in fixed bed or fluidized bed processes.[7, 22, 24] While, easy to imagine for both, magnetic

87 cores have an obvious advantage in highly fluidized bed technologies, especially in newly

88 developed magnetic assisted fluidized bed, due to potentially addressing/alleviating attenuated

89 slugging, channeling, plugging, and agglomeration.[24, 33]

90 In this work, we have methodically designed, synthesized, and evaluated novel core-shell

91 nanocomposites, comprised of a magnetite $\left(\mathrm{Fe}_{3} \mathrm{O}_{4}\right)$ nanoparticle core and tunable surface

92 functionalized organic coatings (shell) as a platform material for advanced $\mathrm{CO}_{2}$ capture,

93 separation, and reuse. Commercial magnetite nanoparticles (nMAG) were chosen due to their

94 ability to respond to an external magnetic field, allowing for potential low-energy

95 placement/recovery in addition to broad material availability needed for scale-up employment.

96 Through methods described, nMAG can be surface coated with PEI, an excellent organic $\mathrm{CO}_{2}$

97 polymeric sorbet, with varied molecular weights $(\mathrm{Mw})$ and structures (linear vs. branched),

98 yielding nanocomposites with tunable coating thickness (PEI loading \%) and combinations of

99 different amine types (primary, secondary, and tertiary amine). Besides PEI-based polymers,

100 other surface polymers were similarly demonstrated and explored, such as poly(acrylic acid)

101 (PAA), poly(sodium 4-styrenesulfonate) (PSS), etc. This methodology provides a simple, green

102 and environmentally friendly procedure to produce scalable, surface tunable, and solid-state

103 magnetic nano-sorbents for $\mathrm{CO}_{2}$ capture. For all, surface coating(s) thermodynamic stability, 
104 polymer loading percentage, specific surface area, and $\mathrm{CO}_{2}$ adsorption/desorption performance

105 were characterized using Fourier transform infrared spectroscopy (FTIR), Brunauer-Emmett-

106 Teller (BET), and thermogravimetric analysis (TGA) instrument. This work, for the first time,

107 systematically evaluates and compares the $\mathrm{CO}_{2}$ capture performance of nMAG with a series of 108 tailored surface coatings. Presented data sets clearly demonstrate the critical role of the outer 109 polymer(s) in determining material performance - providing informative direction(s) to further 110 surface (optimized) modification.

\section{2. MATERIALS AND METHOD}

\section{$112 \quad 2.1$ Materials}

113 Nanoscale magnetite powder (nMAG, catalog \# 637106, iron (II, III) oxide, $<50 \mathrm{~nm}, 98+\%$ ),

114 polyethylenimine (PEI, branched, Mw 25,000), poly(acrylic acid) (PAA, Mw 100,000), 115 poly(sodium 4-styrenesulfonate) (PSS, Mw 70,000), poly(allylamine hydrochloride) (PAH, Mw 116 17,500), poly(ethylene glycol) (PEG, Mw 35,000), and polyvinylpyrrolidone (PVP, Mw 40,000)

117 were all purchased from Sigma-Aldrich. Polyethylenimine (PEI, branched, Mw 1,800), 118 polyethylenimine (PEI, branched, Mw 10,000), and polyethylenimine (PEI, linear, Mw 25,000) 119 were purchased from Polysciences. Reagent grade of ethanol were used without further 120 purification.

$121 \quad 2.2$ Preparation of surface functionalized nMAG

122 nMAG nanoparticles were prepared using a modified polymer impregnation-vaporization 123 method through probe sonication, extensive mixing, and solvent evaporation.[9] For a typical 124 sample preparation, a certain amount of polymer (0.4-2.0 g) was dissolved in $25 \mathrm{~mL}$ ethanol, and 125 then slowly added under stirring to $5.0 \mathrm{~g}$ of nMAG suspended in $25 \mathrm{~mL}$ ethanol. Upon 126 completely mixing, the solution was then probe sonicated (UP 50H, Dr. Hielscher, GMHB) for 
127 an extended period of time under vacuum until almost dry. The mixture was subsequently

128 transferred to a vacuum oven overnight at $50^{\circ} \mathrm{C}$. The obtained polymer impregnated nMAG was

129 brown in color and further ground to fine powder with a mortar and pestle for material

130 characterizations. As-prepared nano-sorbents were dried at $80{ }^{\circ} \mathrm{C}$ in a vacuum oven before use.

131 The final magnetic nanoparticles are denoted as PEI-nMAG, PAA-nMAG, PSS-nMAG, PAH132 nMAG, PEG-nMAG, and PVP-nMAG.

\section{$133 \quad 2.3$ Material characterization}

134 nMAG nanoparticle size was characterized using transmission electron microscopy (TEM, FEI 135 Tecnai G2 Spirit) operated at $120 \mathrm{kV}$. In order to prepare the TEM sample, nMAG nanoparticles 136 were first dispersed in hexane and then a small drop of the NPs suspension was placed on a 137 carbon coated copper grids (Electron Microscopy Sciences) and dried overnight. X-ray powder 138 diffraction (XRD) was performed on a Bruker D8 Advance from 20 to $802 \theta$ degree at room 139 temperature. The measurement was obtained with a LynxEye XE detector and a $\mathrm{Cu} \mathrm{K} \alpha \mathrm{X}$-ray 140 source $(1.54 \AA)$ generated at $40 \mathrm{kV}$ and $40 \mathrm{~mA}$. The magnetization hysteresis loop was analyzed 141 with a superconducting quantum interference device (SQUID) magnetometer (Quantum Design 142 MPMS $5 \mathrm{XL}$ SQUID) at $300 \mathrm{~K}$ (up to $5 \mathrm{~T}$ ) using powders of pristine and polymer grafted nMAG.

143 Solid-state Fourier transform infrared spectra were obtained on a Nexus 470 FTIR spectroscopy

144 (Thermo Nicolet, NC). To prepare the pristine nMAG and polymer functionalized nMAG 145 powders for IR analysis, each sample was mixed with $\mathrm{KBr}$ powder (Spectrograde, International 146 Crystal Lab, NJ) in an optimal 1:3 ratio to achieve a total amount of $40 \mathrm{mg}$. Before each 147 measurement, a $\mathrm{KBr}$ background spectrum was collected and subtracted thereafter. All spectra 148 were performed from $400-4000 \mathrm{~cm}^{-1}$ with a resolution of $2 \mathrm{~cm}^{-1}$. Brunauer-Emmett-Teller (BET) 149 surface area was characterized by $\mathrm{N}_{2}$ adsorption/desorption isotherm measurements on a 
150 Quantachrome NOVA 2000e instrument. The surface area was determined by the multipoint 151 BET method.[28, 34] TGA was performed on a Q5000IR (TA Instruments, USA) with

152 temperature ranging from room temperature to $1000{ }^{\circ} \mathrm{C}$ under an ultra-pure $\mathrm{N}_{2}$ flow with a 153 heating rate of $10^{\circ} \mathrm{C} / \mathrm{min}$.

\section{$154 \quad 2.4$ Adsorption measurements}

$155 \mathrm{CO}_{2}$ adsorption/desorption performance of polymer functionalized nMAG nanoparticles was 156 analyzed using TGA (Q5000IR, TA Instruments) under atmospheric pressure. Ultrahigh purity 157 of $\mathrm{CO}_{2}$ was used for thermogravimetric analysis (TGA). For a typical test, the dried nMAG 158 powder sample (10-50 mg) was placed into a platinum pan and heated up to $105{ }^{\circ} \mathrm{C}$ under $\mathrm{N}_{2}$ 159 flow $(25 \mathrm{~mL} / \mathrm{min})$ for 2 hours until no obvious weight change was observed. This step was to 160 remove trace moisture and any background sorbed $\mathrm{CO}_{2}$ from the sample. The temperature was 161 then lowered to the desired values $\left(20-100{ }^{\circ} \mathrm{C}\right.$ ) and the gas flow was switched to $\mathrm{CO}_{2}$ (up to 1 162 hour). The flow rate of the $\mathrm{CO}_{2}$ gas was maintained at $25 \mathrm{~mL} / \mathrm{min}$. The change in mass of the 163 sample was recorded continuously during the entire measurement. The $\mathrm{CO}_{2}$ adsorption capacity 164 in $\mathrm{mg} \cdot \mathrm{CO}_{2} / \mathrm{g} \cdot$ sorbent was calculated based on the weight change of the samples in the 165 adsorption processes. Regeneration of the nMAG was performed at an elevated temperature (105

$166{ }^{\circ} \mathrm{C}$ ) using a temperature-swing approach by introducing pure $\mathrm{N}_{2}$ into the sample cell. Cyclic 167 adsorption-desorption studies were performed to evaluate the recyclability of these materials for 168 potential real-world application. Sorption measurements of $\mathrm{O}_{2}$ and $\mathrm{N}_{2}$ were carried out similarly.

\section{3. RESULTS AND DISCUSSION}

$170 \quad 3.1$ Material preparation and characterization

171 The general preparation process for nMAG nanoparticles is shown in Figure 1a. Polymer 172 grafting onto nMAG nanoparticles was successfully carried out through a sonication method 
173 followed by evaporation of solvent.[9] The sonication-mixing-evaporation strategy explored here

174 allows for homogeneous and complete incorporation of polymers onto the nMAG surfaces. The

175 primary particle diameter ranged from $10-50 \mathrm{~nm}$ for pristine nMAG nanoparticles as shown in a

176 TEM micrograph (Figure 1b). Figure 1c shows XRD diffraction patterns of pristine nMAG and 177 PEI-nMAG. The diffraction peaks at $30.2^{\circ}, 35.3^{\circ}, 43.0^{\circ}, 53.4^{\circ}, 56.9^{\circ}$, and $62.5^{\circ}$ correspond to 178 the magnetite crystal planes of (220), (311), (400), (422), (511), and (440), respectively. These 179 patterns precisely match the typical cubic spinel magnetite $\left(\mathrm{Fe}_{3} \mathrm{O}_{4}\right)$ structure (JCPDS card \# 19180 0629). The crystal domain size of pristine nMAG is derived from the (311) plan refraction using 181 Scherrer equation:

$$
\mathrm{d}=K \lambda / \beta \cos \theta
$$

183 where $\theta$ is the reference peak position, $\lambda$ is the $\mathrm{X}$-ray wave length ( $0.154 \mathrm{~nm}$ for $\mathrm{Cu} \mathrm{K} \alpha$ line), $\beta$ is 184 the full width at half maximum of the reference peak and $K$ is the shape factor ( 0.9 in this 185 case).[32, 35, 36] For samples tested, average particle size calculated was $22.7 \mathrm{~nm}$. Diffraction 186 patterns of nMAG before and after PEI coating were similar, indicating the high crystallinity of 187 magnetite nanoparticles is preserved during polymer grafting. The magnetic properties of pristine 188 nMAG and PEI-nMAG were characterized with SQUID at $300 \mathrm{~K}$ and the hysteresis loops are 189 shown in Figure 1d. The pristine nMAG and PEI-nMAG are paramagnetic with the coercivity of 19097.0 Oe and 82.5 Oe. The saturation magnetization $\left(\mathrm{M}_{\text {sat }}\right)$ values were 81.1 and $60.7 \mathrm{emu} / \mathrm{g}$ for 191 pristine nMAG and PEI-nMAG (branched, Mw 25,000), respectively. Compared to pristine 192 nMAG, PEI-nMAG demonstrated relatively lower $\mathrm{M}_{\text {sat }}$, possibly due to the incorporation of PEI 193 layer on the nMAG surface,[29] as surface polymers on nMAG surface likely impede the 194 tendency of direct particle-particle contact. Such magnetic properties allow for simple separation 195 processes for material collection and recycling while also saving energy, compared to other 
196 separation technologies.[29] As shown in Figure 1e, nMAG nano-composites are strongly 197 attracted to a small magnet $(<1.5 \mathrm{~T})$.

\section{$198 \quad 3.2$ FTIR analysis}

199 The FTIR spectra of the pristine and polymer functionalized nMAG are reported in Figure 2. 200 The peak at $598 \mathrm{~cm}^{-1}$ is assigned to the stretching vibration of $\mathrm{Fe}-\mathrm{O}-\mathrm{Fe}$ in pristine nMAG $\left(\mathrm{Fe}_{3} \mathrm{O}_{4}\right)$ 201 (Figure 2a). We found the characteristic peaks of PEI from the PEI-nMAG (Figure 2b), such as 202 the $-\mathrm{N}-\mathrm{H}$ stretching at $3272 \mathrm{~cm}^{-1},-\mathrm{C}-\mathrm{H}$ stretching at $2940 \mathrm{~cm}^{-1}$ and $2815 \mathrm{~cm}^{-1},-\mathrm{N}-\mathrm{H}$ bending at $2031576 \mathrm{~cm}^{-1},-\mathrm{C}-\mathrm{H}$ bending at $1465 \mathrm{~cm}^{-1}$, and $-\mathrm{C}-\mathrm{N}$ stretching at $1300 \mathrm{~cm}^{-1}$.[37] For PAA-nMAG, a 204 strong band is shown at $1720 \mathrm{~cm}^{-1}$, which is the characteristic peak of $\mathrm{C}=\mathrm{O}$ stretching (Figure 205 2c).[38, 39] The weaker band at $1451 \mathrm{~cm}^{-1}$ is associated with $-\mathrm{CH}_{2}$ deformation. Response at 2061413,1248 and $1178 \mathrm{~cm}^{-1}$ are attributed to $\mathrm{C}-\mathrm{O}$ stretching coupled with O-H in-plane 207 bending.[40] Two peaks at 1600 and $1503 \mathrm{~cm}^{-1}$ are from the asymmetric and symmetric bending 208 vibrations of $-\mathrm{NH}_{3}{ }^{+}$in the PAH-nMAG (Figure 2d).[41] For PEG-nMAG (Figure 2e), the 209 absorption band at $2878 \mathrm{~cm}^{-1}$ is due to $\mathrm{C}-\mathrm{H}$ stretching. Two peaks at $1464 \mathrm{~cm}^{-1}$ and $1343 \mathrm{~cm}^{-1}$ 210 are ascribed to $\mathrm{C}-\mathrm{H}$ bending vibrations. $\mathrm{O}-\mathrm{H}$ and $\mathrm{C}-\mathrm{O}-\mathrm{H}$ stretching can be found at $1279 \mathrm{~cm}^{-1}$ 211 and $1094 \mathrm{~cm}^{-1}$, respectively.[42] For PSS-nMAG, two bands at $1000 \mathrm{~cm}^{-1}$ and $1040 \mathrm{~cm}^{-1}$ are

212 attributed to the $\mathrm{S}=\mathrm{O}$ stretching vibration (Figure 2f).[43] For PVP-nMAG, characteristic peaks

213 of pyrrolidinyl group are shown at $1463 \mathrm{~cm}^{-1}$ and $1424 \mathrm{~cm}^{-1}$. The peak at $1678 \mathrm{~cm}^{-1}$ is due to $214 \mathrm{C}=\mathrm{O}$ vibrations and the peak at $1290 \mathrm{~cm}^{-1}$ is assigned to $\mathrm{C}-\mathrm{N}$ vibrations in PVP (Figure 2g).[44, 215 45] FTIR spectra confirm all polymers (e.g. PEI, PAA, PAH, etc.) were successfully coated onto 216 nMAG surface though intensively mixing and sonication as described above.

\section{$217 \quad 3.3$ Thermal stability}


Thermal stability of the sorbents is an important factor to be considered for real-world

219 applications, especially in power plant related CCS technologies. Here, the thermal stabilities of

220 different polymer grafted nMAG nanoparticles were quantified by thermogravimetric analysis

221 (TGA) under an ultra-pure $\mathrm{N}_{2}$ atmosphere. Figure 3a depicts the TGA thermal stability curves

222 for pristine nMAG and PEI-nMAG with different PEI loading and PEI types (low vs. high Mw;

223 branched vs. linear). Pristine nMAG shows high stability with negligible weight loss (0.6\%) up

224 to temperature of $1000{ }^{\circ} \mathrm{C} .[29]$ Four PEI-nMAG samples with different PEI loadings (same Mw

225 of 25,000 and branched structure) were prepared and evaluated here. These samples did not start

226 to decompose until ca. $160{ }^{\circ} \mathrm{C}$, indicating good thermal stability. The slight weight loss $(<1 \%)$

227 below this temperature is attributed to loss of adsorbed water or other associated, small volatiles.

228 Observable weight loss starts from ca. $200{ }^{\circ} \mathrm{C}$, until all the coatings were completely

229 decomposed and released around $700{ }^{\circ} \mathrm{C}$. The amount of PEI in the PEI-nMAG was calculated

230 based on the weight loss curve. TGA profiles indicate that ca. $6 \%, 12 \%, 16 \%$, and $26 \%$ of

231 (wt/wt \%) PEI (branched, Mw 25,000) was grafted onto the four PEI-nMAG samples,

232 respectively. This result confirms that the higher PEI loading amount can be obtained through

233 the addition of additional PEI polymer during preparation. The PEI loading was between 16-17

$234 \%$ for functionalized nMAG prepared using lower molecular weight PEI (Mw 1,800 and 10,000)

235 and linear PEI (Mw 25,000). The sonication-mixing-evaporation strategy also allowed for the

236 preparation of surface functionalization nMAG with similar PEI loading (16\%) from different

237 PEI sources, which is important for the direct comparison of their $\mathrm{CO}_{2}$ capture performance. The

238 thermal stability of other polymer functionalized nMAG was measured in the same way and

239 shown in Figure 3b. TGA curves show all other polymers (PAA-nMAG, PAH-nMAG, PEG- 
nMAG, PSS-nMAG, and PVP-nMAG) evaluated were also stable below $200{ }^{\circ} \mathrm{C}$ with similar

241 weight percentages ca. 17-18\% mass loading (Figure 3b).

\section{$242 \quad 3.4$ BET surface area}

243 The Brunauer-Emmett-Teller (BET) method was used to determine the specific surface area of 244 nMAG with resulting data presented in Table 1. The specific surface area of the pristine nMAG 245 was $39.6 \mathrm{~m}^{2} / \mathrm{g}$ and polymer coatings were found to reduce the surface area of the 246 nanocomposites. For PEI-nMAG (branched, Mw 25,000), when PEI loading increases from 6\% 247 to $26 \%$, the specific surface area significantly decreases from $32.2 \mathrm{~m}^{2} / \mathrm{g}$ to $3.61 \mathrm{~m}^{2} / \mathrm{g}$. For other 248 samples, nMAG exhibit surface area ranging from $12.4 \mathrm{~m}^{2} / \mathrm{g}$ to $35.5 \mathrm{~m}^{2} / \mathrm{g}$, depending on the 249 coating type and loading.

\section{$250 \quad 3.5 \mathrm{CO}_{2}$ sorption}

251 The $\mathrm{CO}_{2}$ sorption measurements were determined by TGA at atmospheric pressure. The effect 252 of PEI (branched, $\mathrm{Mw}$ 25,000) loading (weight percentage) on $\mathrm{CO}_{2}$ sorption performance was 253 evaluated under pure $\mathrm{CO}_{2}$ atmosphere at $25^{\circ} \mathrm{C}$ (Figure 4a). Sorption capacities of 6.1, 11.6, 15.0 254 and $6.1 \mathrm{mg} / \mathrm{g}$ were observed for the PEI-nMAG samples with $6 \%, 12 \%, 16 \%$, and $26 \%$ PEI 255 loading, respectively. $\mathrm{CO}_{2}$ adsorption capacity increased with increasing PEI loading from $6 \%$ 256 to $16 \%$, and then decreased at higher PEI loading of $26 \%$. The further increase of PEI loading 257 amount reduced the specific surface area of the nMAG from $39.6 \mathrm{~m}^{2} / \mathrm{g}$ to $3.6 \mathrm{~m}^{2} / \mathrm{g}$, leading to an 258 overall lower $\mathrm{CO}_{2}$ sorption capacity. In a previous study by $\mathrm{Xu}$ et al., the highest sorption 259 capacity for MCM-41-PEI sorbent was obtained when the PEI loading is $50 \mathrm{wt} \%$, due to the 260 combination of increasing $\mathrm{CO}_{2}$ affinity sites and decreasing surface area and pore

261 size/volume.[8] Labreche et al. also observed a maximum $\mathrm{CO}_{2}$ capacity of $1.25 \mathrm{mmol} / \mathrm{g}$-fiber 262 when the PEI loading was chosen at a moderate concentration of $10 \mathrm{wt} \%$.[22] $\mathrm{The}^{\mathrm{CO}_{2}}$ 
263 capacities were lowered when the PEI concentrations were either decreased or increased. Yu et

264 al. concluded that $\mathrm{CO}_{2}$ uptake capacity is not directly linked to the amine loading since the

265 aggregation of amine may form on supports, leading to reduced accessibility with regard to

$266 \mathrm{CO}_{2} \cdot[10]$ Overall, in this study, PEI-nMAG with $16 \%$ PEI exhibits the highest adsorption

267 capacity towards $\mathrm{CO}_{2}$, which was further studied.

268 Figure $4 \mathrm{~b}$ shows $\mathrm{CO}_{2}$ uptake as a function of time for nMAG coated with different PEI 269 types but with similar PEI loadings (ca. $16 \mathrm{wt} / \mathrm{wt} \%$ ). For these, the time needed to absorb

$27090 \%$ of the total $\mathrm{CO}_{2}$ uptake is ca. $25 \mathrm{~min}$, indicating the sorption processes occur 271 relatively quickly. The $\mathrm{CO}_{2}$ adsorption capacities were $14.0 \mathrm{mg} / \mathrm{g}, 14.6 \mathrm{mg} / \mathrm{g}$, and 15.0

$272 \mathrm{mg} / \mathrm{g}$ for nMAG with branched PEI 1,800, PEI 10,000, and PEI 25,000, respectively. 273 nMAG coated with linear PEI (Mw 25,000) show a $\mathrm{CO}_{2}$ sorption capacity of $16.4 \mathrm{mg} / \mathrm{g}$, 274 higher than the nMAG decorated with branched PEI (Mw 25,000). Under dry conditions, 275 only the primary and secondary amines of branched PEI react with $\mathrm{CO}_{2}$ to form 276 carbamate salts with a molar ratio of $2: 1$ (carbamate formation: $2 \mathrm{R}_{1} \mathrm{R}_{2} \mathrm{NH}+\mathrm{CO}_{2}=$ $277 \mathrm{R}_{1} \mathrm{R}_{2} \mathrm{NCOO}^{-}+\mathrm{R}_{1} \mathrm{R}_{2} \mathrm{NH}_{2}{ }^{+}$), however, the tertiary amine (ca. $25 \%$ ) from branched PEI 278 does not typically undergo complexation with $\mathrm{CO}_{2}$.[46] In case of linear PEI, only 279 secondary amines are present.

280 Figure 5 presents $\mathrm{CO}_{2}$ sorption capacities of nMAG with varied surface coatings $\left(25^{\circ} \mathrm{C}\right) . \mathrm{CO}_{2}$ 281 adsorption capacities were $0.7 \mathrm{mg} / \mathrm{g}, 1.1 \mathrm{mg} / \mathrm{g}, 1.3 \mathrm{mg} / \mathrm{g}, 2.2 \mathrm{mg} / \mathrm{g}$, and $1.7 \mathrm{mg} / \mathrm{g}$, for PAA282 nMAG, PAH-nMAG, PEG-nMAG, PSS-nMAG, and PVP-nMAG, respectively. Compared to 283 PEI-nMAG (branched, Mw 25,000, $16 \mathrm{wt} / \mathrm{wt} \%$ ) sorbents, other surface coating polymers 284 demonstrate substantially lower $\mathrm{CO}_{2}$ sorption capacities. Similar trends have been reported by 285 others. Jiang et al. found the substantial decrease in $\mathrm{CO}_{2}$ capture capacity when the 
polyelectrolyte was switched to PAA or PAH.[21] For these systems, PEI-nMAG are superior in

$287 \mathrm{CO}_{2}$ capture, due to the specific chemical bonding between basic amine functional groups and

288 acidic $\mathrm{CO}_{2}$ molecules compared to other polymers investigated.[1, 10]

$289 \quad 3.6 \mathrm{CO}_{2}$ sorption-PEI-nMAG selectivity

290 For practical application, solid sorbent will need to selectively capture $\mathrm{CO}_{2}$ from gas mixtures.

291 As an example, $\mathrm{N}_{2}$ is the major component in typical flue gas.[27] The sorption capacity of PEI-

292 nMAG $(16 \mathrm{wt} / \mathrm{wt} \%$, branched, $\mathrm{Mw} 25,000)$ towards $\mathrm{N}_{2}$ and $\mathrm{O}_{2}$ were evaluated and shown in

293 Figure 6. PEI-nMAG shows $0.18 \mathrm{mg} / \mathrm{g}$ adsorption capacity for $\mathrm{N}_{2}$ and $0.13 \mathrm{mg} / \mathrm{g}$ adsorption

294 capacity for $\mathrm{O}_{2}$, thus demonstrating high selectivity for $\mathrm{CO}_{2}$ over $\mathrm{N}_{2}$ and $\mathrm{O}_{2}$. On-going studies

295 are exploring more complicated and real-world gas mixtures.

$296 \quad 3.7$ Temperature effect

297 Figure 7 shows $\mathrm{CO}_{2}$ adsorption capacity as a function of temperature $\left(25^{\circ} \mathrm{C}\right.$ to $\left.100{ }^{\circ} \mathrm{C}\right)$ for

298 PEI-nMAG (16 wt/wt \%, branched, Mw 25,000) with sorption capacities of $15.0 \mathrm{mg} / \mathrm{g}, 17.1$

$299 \mathrm{mg} / \mathrm{g}, 18.0 \mathrm{mg} / \mathrm{g}, 18.8 \mathrm{mg} / \mathrm{g}, 17.5 \mathrm{mg} / \mathrm{g}$, and $13.1 \mathrm{mg} / \mathrm{g}$ at $25^{\circ} \mathrm{C}, 40{ }^{\circ} \mathrm{C}, 50{ }^{\circ} \mathrm{C}, 60^{\circ} \mathrm{C}, 80{ }^{\circ} \mathrm{C}$, and

$300100{ }^{\circ} \mathrm{C}$, respectively. $\mathrm{CO}_{2}$ uptake first increases when the temperature increases to $60{ }^{\circ} \mathrm{C}$ and

301 then decreases as temperature is increased to $120{ }^{\circ} \mathrm{C}$. At lower temperatures, bulk phase

302 aggregation of PEI on the nMAG surface results in diffusion-limited adsorption of $\mathrm{CO}_{2}$

303 molecules with lower uptake capacity.[47] As reported by others, when temperature is further

304 increased, PEI chains become more flexible as the viscosity of PEI decreases, thus allowing for

305 easier $\mathrm{CO}_{2}$ access to active sorption sites.[5, 15] Similar observations were also reported by Meth

306 et al. who examined the adsorption capacity of $\mathrm{CO}_{2}$ vs. temperature ranging from $30-100{ }^{\circ} \mathrm{C}$ for

307 fumed silica impregnated with PEI and found the maximum $\mathrm{CO}_{2}$ uptake at a moderate

308 temperature of $50{ }^{\circ} \mathrm{C} .[15]$ The decrease of sorption capacity at higher temperatures is attributed 
309 to the more favorable equilibrium towards desorption processes.[15] These results indicate the

310 PEI-nMAG is also suitable for $\mathrm{CO}_{2}$ capture, even at the elevated temperatures of flue gas (50-

$\left.311 \quad 120^{\circ} \mathrm{C}\right) \cdot[2]$

$312 \quad 3.8$ Recyclability

313 In addition to high sorption capacities, sorbents with superior regenerative ability

314 (recyclability) to undergo multiple adsorption/desorption cycles are technically and economically

315 preferable. Typically, regeneration of (gas) sorbents can be achieved by either controlled

316 pressure or temperature swings. Here, a temperature swing method was used to regenerate

317 sorbents and test the recyclability of the materials during $\mathrm{CO}_{2}$ sorption/desorption events. Figure

3188 presents $\mathrm{CO}_{2}$ recyclability of PEI-nMAG sorbents (branched, Mw 25,000, $16 \mathrm{wt} / \mathrm{wt} \%$ ) for 20

319 cycles. $\mathrm{CO}_{2}$ sorption capacity is $14.1 \mathrm{mg} / \mathrm{g}$ after 20 cycles, with slight (ca. 6\%) drop in

320 performance as compared to the initial capacity $(15.0 \mathrm{mg} / \mathrm{g})$. Since the desorption was carried out

321 at $105{ }^{\circ} \mathrm{C}$ under dry conditions which is lower than the formation temperature of urea (above 135

$322{ }^{\circ} \mathrm{C}$ ),[48] the slight decrease in $\mathrm{CO}_{2}$ sorption capacity may result from the loss of outer weakly

323 bound PEI from nMAG surfaces during temperature swing regeneration processes.[9] The

324 overall the excellent regenerative ability of PEI-nMAG nanocomposites can be attributed to the

325 low volatility of PEI, strong interaction between PEI and nMAG, and good thermal stability.[10,

$32611,28]$

327 4. Conclusions

328 nMAG-based, surface tunable, nanocomposite materials demonstrated in this study can be

329 simply and reproducibly prepared from commercially available materials. PEI-nMAG show

330 significantly higher sorption capacity for $\mathrm{CO}_{2}$ compared to other polymer-based, surface

331 functionalized nMAG composite materials. In addition, PEI-nMAG nanocomposites exhibit 
332 enhanced $\mathrm{CO}_{2}$ capture performance even at elevated temperature $\left(40-80{ }^{\circ} \mathrm{C}\right)$, which is ideal for 333 post-combustion $\mathrm{CO}_{2}$ capture. Further, PEI-nMAG can be used for multiple sorption / desorption 334 (separation) cycles while maintaining high performance. Taken together, cost effectiveness, 335 facile and scalable preparation routes, high $\mathrm{CO}_{2}$ sorption capacities, magnetic susceptibility, and 336 good recyclability underpin these hybrid nanocomposites as a potentially attractive CCS material 337 platform. On-going material evaluation includes $\mathrm{CO}_{2}$ capture experiments for simulated and real 338 flue-gas streams. 

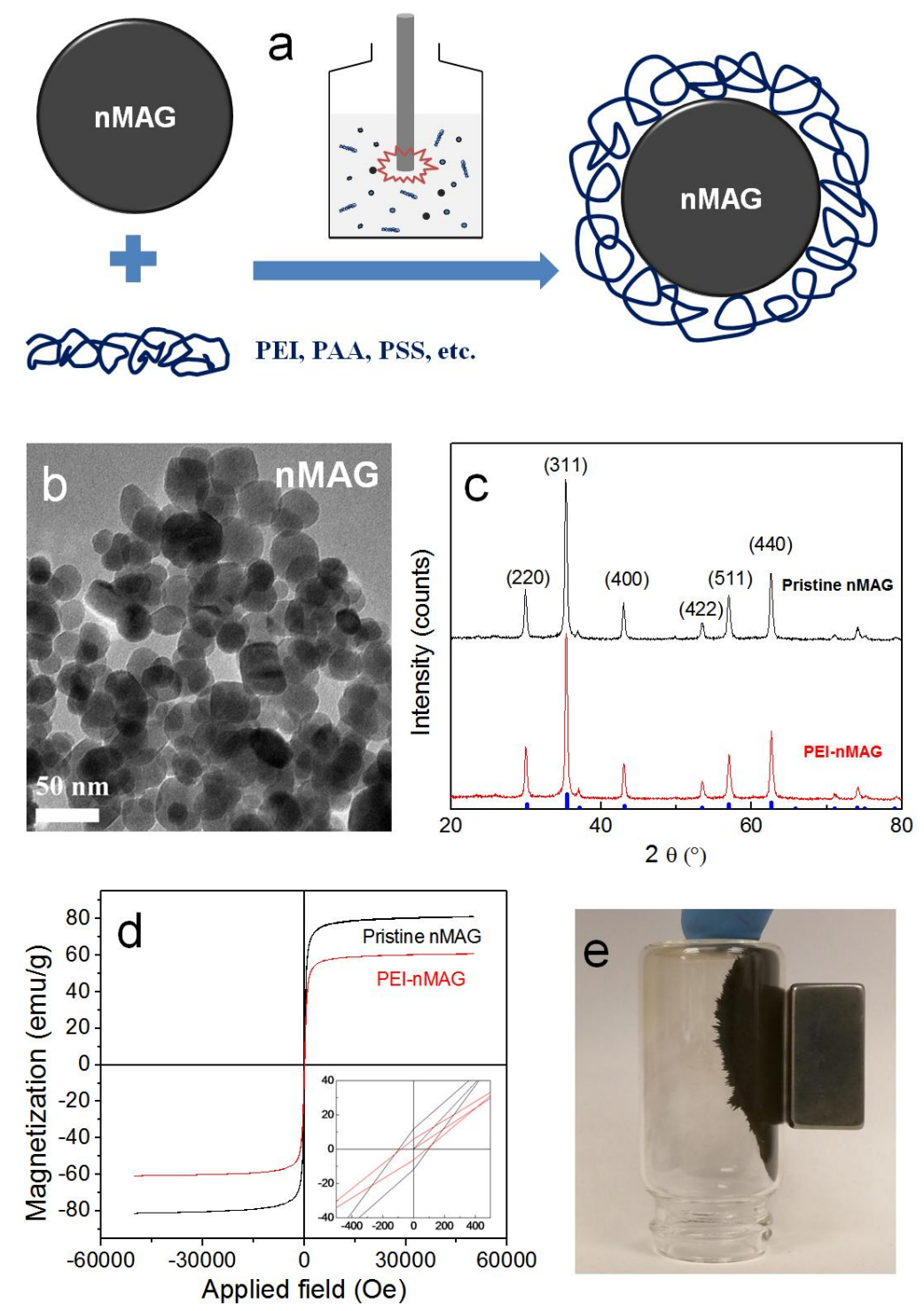

340 Figure 1. (a) Scheme for the preparation of polymer impregnated nMAG through sonication, (b)

341 TEM micrograph of pristine nMAG, (c) XRD patterns of nMAG and PEI-nMAG, the blue 342 vertical lines correspond to JCPDS card of $\mathrm{Fe}_{3} \mathrm{O}_{4}$ (JCPDS card \# 19-0629), (d) The 343 magnetization curves of nMAG and PEI-nMAG, and (e) photograph of PEI-nMAG response to a 344 magnet. 


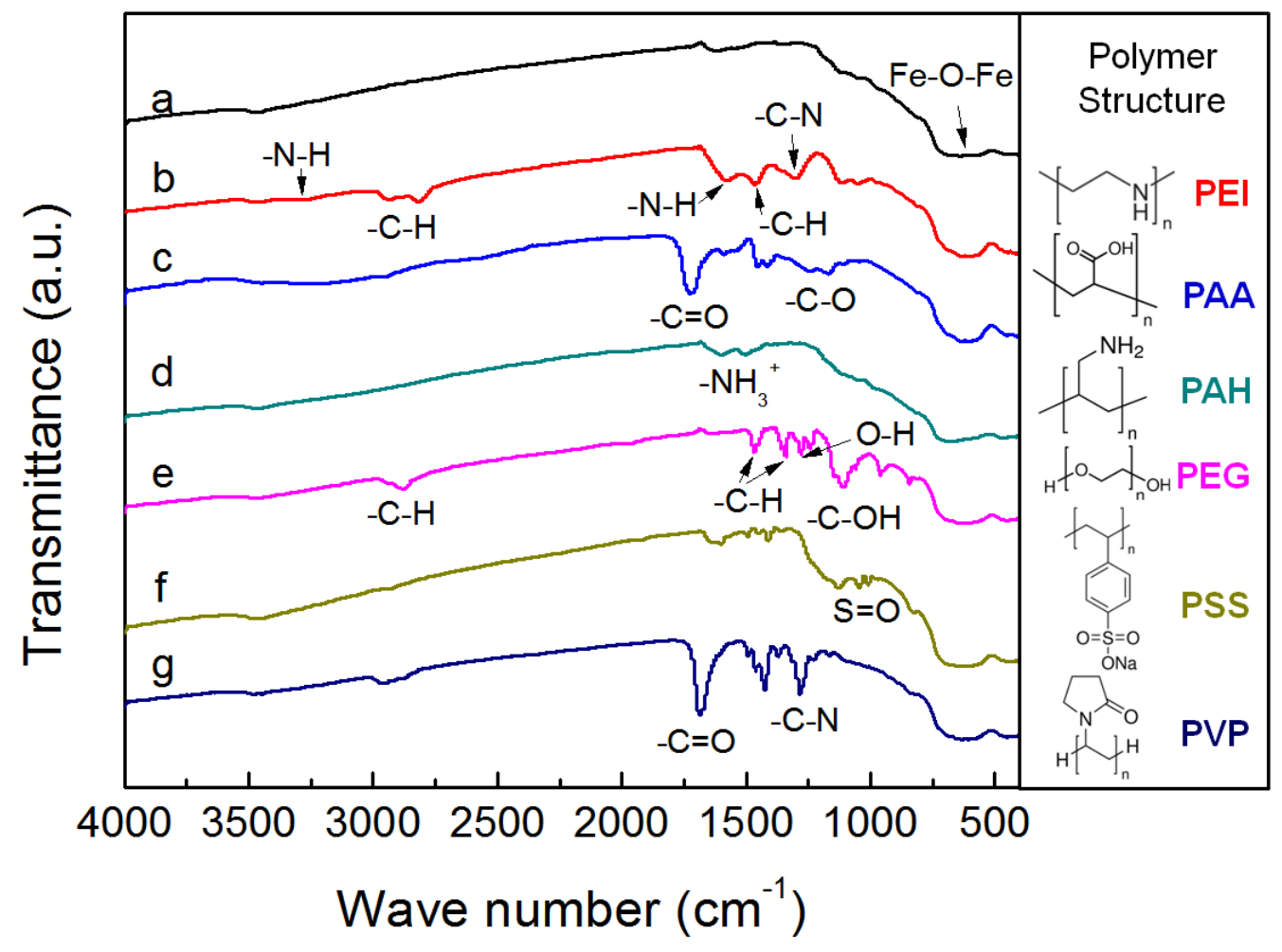

346 Figure 2. FTIR spectra of the pristine and functionalized nMAG: (a) pristine nMAG, (b) PEI-

347 nMAG (branched, Mw 25,000), (c) PAA-nMAG, (d) PAH-nMAG, (e) PEG-nMAG, (f) PSS-

348 nMAG, and (g) PVP-nMAG. The right column of the figure shows the chemical structure of 349 each polymer used in this study. 

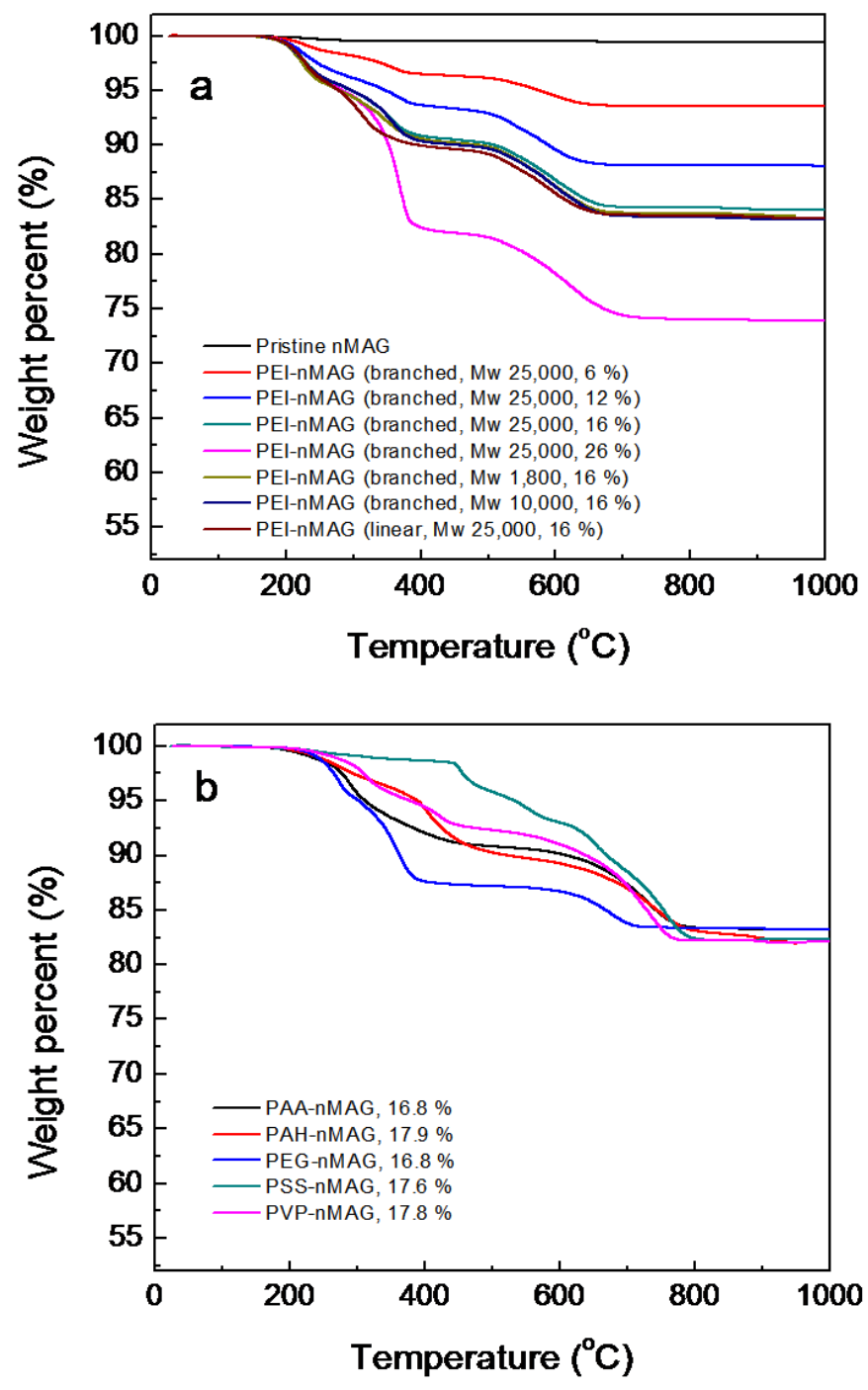

351 Figure 3. TGA thermal stability curves of different nMAG $\left(\mathrm{N}_{2}\right.$ atmosphere, $10{ }^{\circ} \mathrm{C} / \mathrm{min}$ heating 352 rate): (a) the pristine nMAG and various PEI-nMAG, and (b) PAA-nMAG, PAH-nMAG, PEG353 nMAG, PSS-nMAG, and PVP-nMAG. 
354 Table 1. Specific surface area of the pristine and functionalized nMAG used in this study as 355 measured by BET.

\begin{tabular}{|c|c|c|c|}
\hline Sample & Surface area $\left(\mathrm{m}^{2} / \mathrm{g}\right)$ & Sample & Surface area $\left(\mathrm{m}^{2} / \mathrm{g}\right)$ \\
\hline Pristine $\mathrm{nMAG}$ & 39.6 & PSS-nMAG & 35.5 \\
\hline PEI-nMAG (branched, Mw 25,000, 6 \%) & 32.2 & PAA-nMAG & 19.4 \\
\hline PEI-nMAG (branched, Mw 25,000, $12 \%$ ) & 25.9 & PAH-nMAG & 33.7 \\
\hline PEI-nMAG (branched, Mw 25,000, $16 \%$ ) & 16.5 & PVP-nMAG & 19.2 \\
\hline PEI-nMAG (branched, Mw 25,000, $26 \%$ ) & 3.6 & PEG-nMAG & 23.8 \\
\hline PEI-nMAG (branched, Mw 1,800, 16 \%) & 12.4 & & \\
\hline PEI-nMAG (branched, Mw 10,000, $16 \%$ ) & 13.1 & & \\
\hline PEI-nMAG (linear, Mw 25,000, $16 \%$ ) & 18.9 & & \\
\hline
\end{tabular}



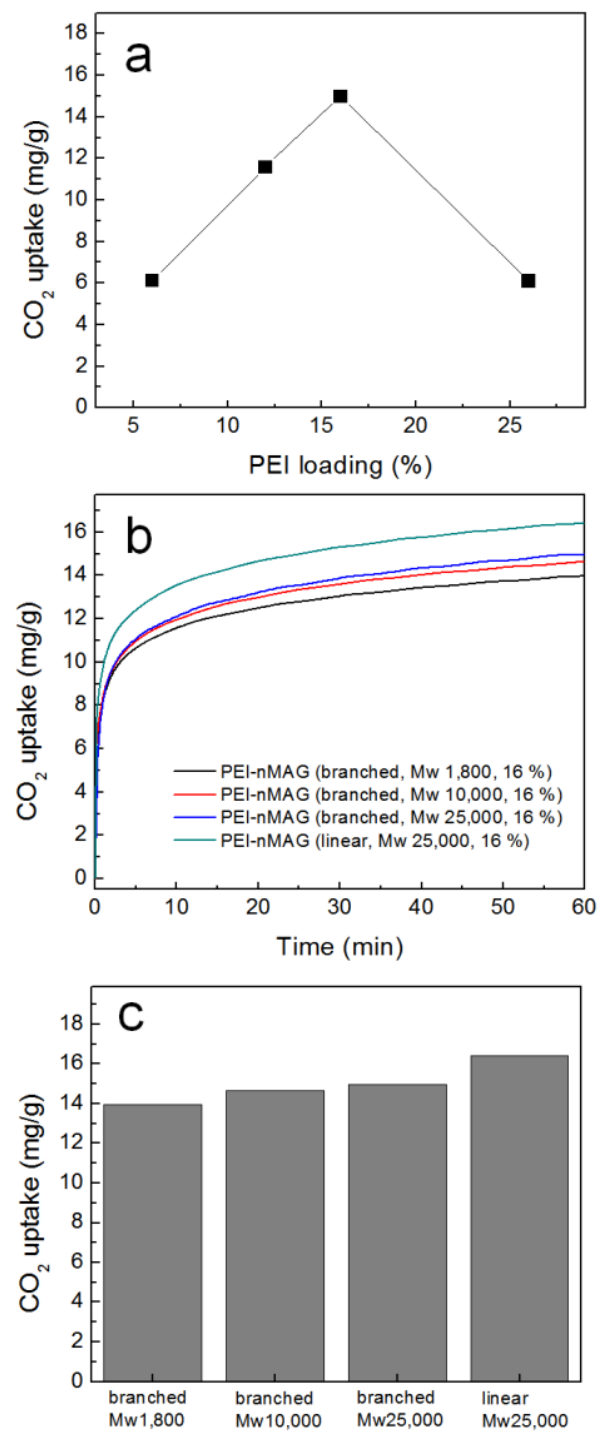

358 Figure 4. Effect of PEI loading and type on $\mathrm{CO}_{2}$ sorption. (a) $\mathrm{CO}_{2}$ adsorption of PEI-nMAG 359 sorbents with various PEI loading amount (branched, Mw 25,000, loading amount from $6 \%$ to $36026 \%$ ) at $25{ }^{\circ} \mathrm{C}, 1$ atm $\mathrm{CO}_{2}$, (b) $\mathrm{CO}_{2}$ sorption onto different PEI-nMAG sorbents, and (c) $\mathrm{CO}_{2}$ 361 adsorption capacity of various PEI-nMAG sorbents with similar PEI loading (16 wt/wt \%). 


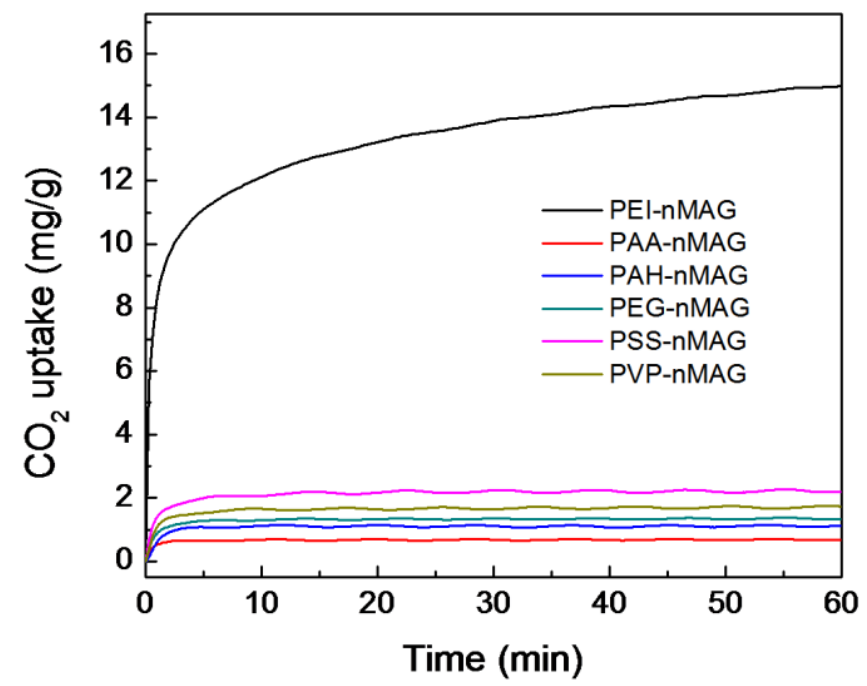

363 Figure 5. Adsorption of $\mathrm{CO}_{2}$ at $25^{\circ} \mathrm{C}$ for PEI-nMAG (branched, $\mathrm{Mw} 25,000,16 \%$ ), PAA-

364 nMAG, PAH-nMAG, PEG-nMAG, PSS-nMAG, and PVP-nMAG. 


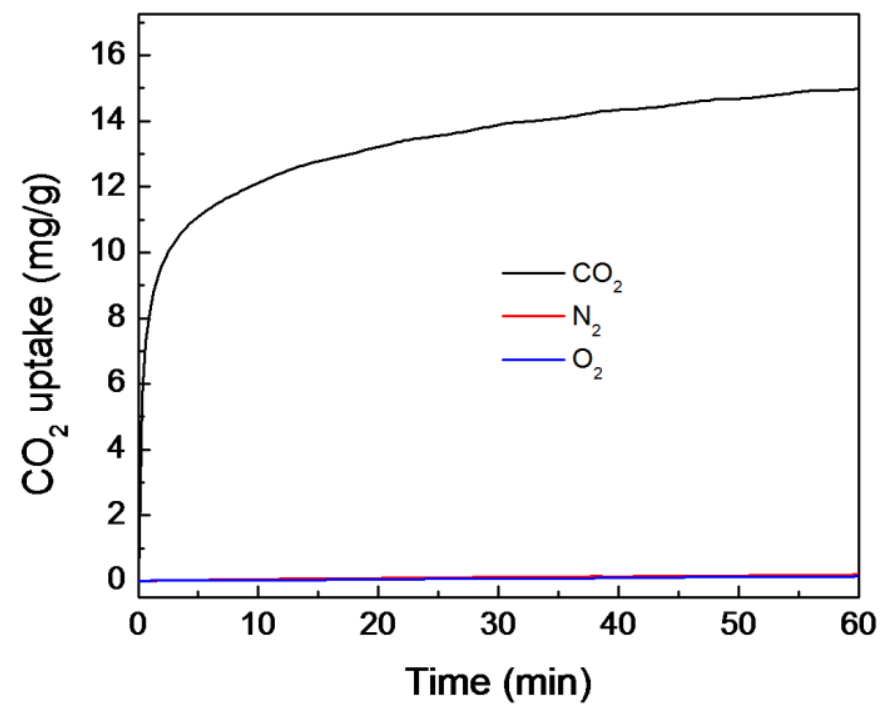

366 Figure 6. Selective adsorption of $\mathrm{CO}_{2}$ over $\mathrm{N}_{2}$ and $\mathrm{O}_{2}$ for PEI-nMAG (branched, Mw 25,000, 16 $367 \%)$ at $25^{\circ} \mathrm{C}$. 


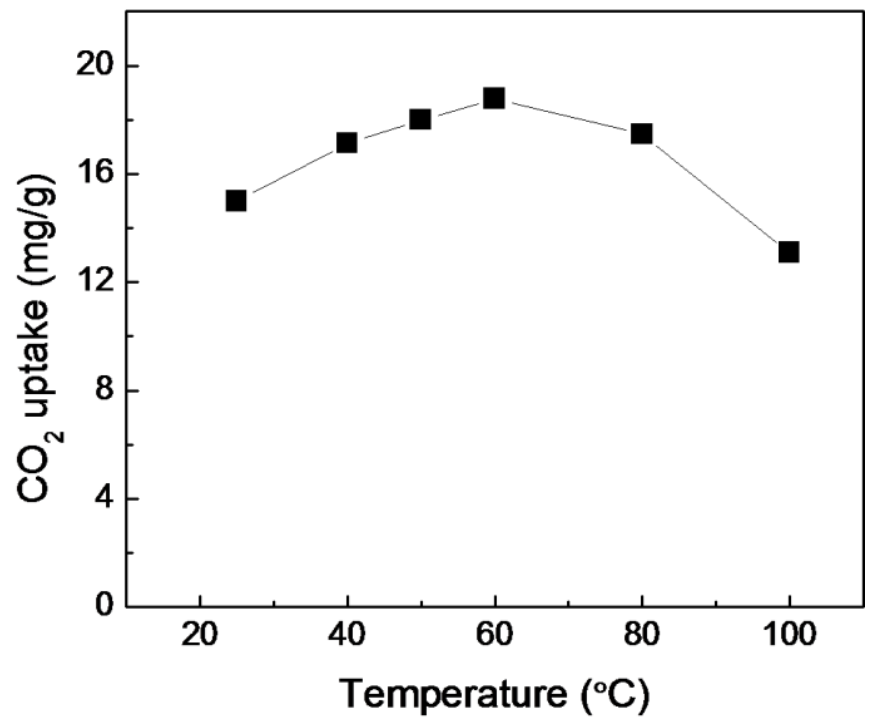

368

369 Figure 7. $\mathrm{CO}_{2}$ adsorption of PEI-nMAG (branched, $\mathrm{Mw} 25,000,16 \%$ ) sorbent at 25, 40, 50, 60, 37080 , and $100^{\circ} \mathrm{C}$. 


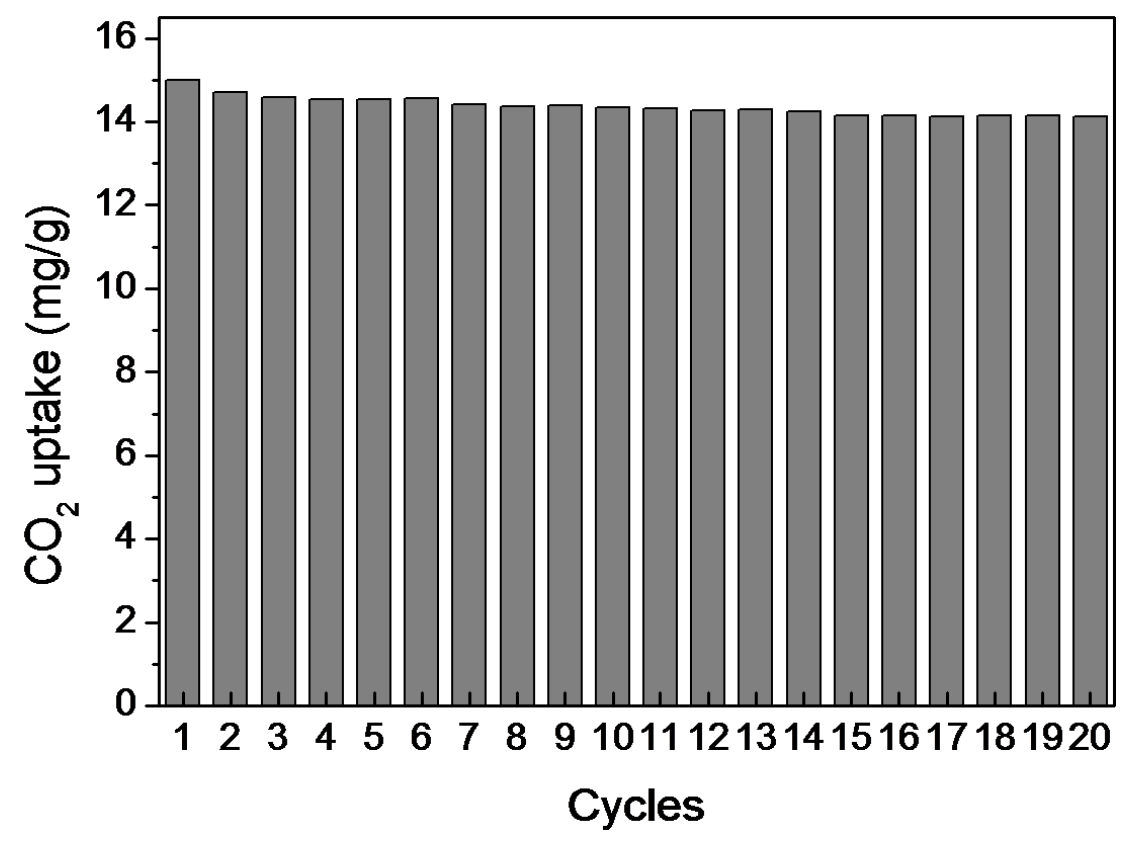

372 Figure 8. $\mathrm{CO}_{2}$ adsorption-desorption cycles of PEI-nMAG (branched, Mw 25,000, 16 \%). For

373 each cycle, nano-sorbents were flushed with $\mathrm{CO}_{2}$ at $25^{\circ} \mathrm{C}$ for 60 min and then flushed with $\mathrm{N}_{2}$ at

$374105{ }^{\circ} \mathrm{C}$ for $15 \mathrm{~min}$. The gas flow rate was set at $25 \mathrm{~mL} / \mathrm{min}$ and 1 atm $\mathrm{CO}_{2}$ or $\mathrm{N}_{2}$ was used under 375 dry condition. 


\section{Corresponding Author}

$378 *$ To whom correspondence should be addressed:

379 John D. Fortner: Tel: +1-314-935-9293; Fax: +1-314-935-5464; Email: jfortner@wustl.edu

\section{Acknowledgments}

381 Financial support of this work by Consortium for Clean Coal Utilization at Washington 382 University in St. Louis is gratefully acknowledged. TEM analysis was provided by the Nano 383 Research Facility (NRF) at Washington University in St. Louis, a member of the National 384 Nanotechnology Infrastructure Network (NNIN), which is supported by the NSF (\#ECS385 0335765). XRD measurements were made possible by a grant from the U.S. National Science 386 Foundation (EAR-1161543). All SQUID measurements were performed at the UCSB MRL 387 Shared Experimental Facility, which is supported by the NSF MRSEC Program Award No. 388 DMR 1121053 (and is a member of the NSF-funded Materials Research Facilities Network). 
390 [1] Q. Wang, J. Luo, Z. Zhong, A. Borgna, CO2 capture by solid adsorbents and their applications: current status and new trends, Energy \& Environmental Science 4 (2011) 42-55.

[2] A. Kaithwas, M. Prasad, A. Kulshreshtha, S. Verma, Industrial wastes derived solid adsorbents for CO2 capture: A mini review, Chemical Engineering Research and Design 90 (2012) 1632-1641.

[3] A.K. Mishra, S. Ramaprabhu, Enhanced CO2 capture in Fe3O4-graphene nanocomposite by physicochemical adsorption, Journal of Applied Physics 116 (2014) 064306.

[4] ESRL, ESRL's Global Monitoring Division, Trends in Atmospheric Carbon Dioxide, (2015).

[5] R.B. Vieira, H.O. Pastore, Polyethylenimine-Magadiite Layered Silicate Sorbent for CO2 Capture, Environmental Science \& Technology 48 (2014) 2472-2480.

[6] J. Baltrusaitis, J. Schuttlefield, E. Zeitler, V.H. Grassian, Carbon dioxide adsorption on oxide nanoparticle surfaces, Chemical Engineering Journal 170 (2011) 471-481.

[7] D.M. D'Alessandro, B. Smit, J.R. Long, Carbon Dioxide Capture: Prospects for New Materials, Angewandte Chemie International Edition 49 (2010) 6058-6082.

[8] X. Xu, C. Song, J.M. Andresen, B.G. Miller, A.W. Scaroni, Novel PolyethylenimineModified Mesoporous Molecular Sieve of MCM-41 Type as High-Capacity Adsorbent for CO2 Capture, Energy \& Fuels 16 (2002) 1463-1469.

[9] X. Wang, N.G. Akhmedov, Y. Duan, D. Luebke, D. Hopkinson, B. Li, Amino AcidFunctionalized Ionic Liquid Solid Sorbents for Post-Combustion Carbon Capture, ACS Applied Materials \& Interfaces 5 (2013) 8670-8677.

[10] C.H. Yu, C.H. Huang, C.S. Tan, A Review of CO2 Capture by Absorption and Adsorption, Aerosol Air Qual. Res. 12 (2012) 745-769.

[11] A.K. Mishra, S. Ramaprabhu, Nano magnetite decorated multiwalled carbon nanotubes: a robust nanomaterial for enhanced carbon dioxide adsorption, Energy \& Environmental Science 4 (2011) 889-895.

[12] Z. Wang, W.A. Mitch, Influence of Dissolved Metals on N-Nitrosamine Formation under Amine-based CO2 Capture Conditions, Environmental Science \& Technology 49 (2015) 1197411981.

[13] K.M.K. Yu, I. Curcic, J. Gabriel, S.C.E. Tsang, Recent Advances in CO2 Capture and Utilization, ChemSusChem 1 (2008) 893-899.

[14] X. Lu, D. Jin, S. Wei, Z. Wang, C. An, W.Y. Guo, Strategies to enhance CO2 capture and separation based on the engineering adsorbent materials, Journal of Materials Chemistry A (2015).

[15] S. Meth, A. Goeppert, G.K.S. Prakash, G.A. Olah, Silica Nanoparticles as Supports for Regenerable CO2 Sorbents, Energy \& Fuels 26 (2012) 3082-3090.

[16] M. Saleh, J.N. Tiwari, K.C. Kemp, M. Yousuf, K.S. Kim, Highly Selective and Stable Carbon Dioxide Uptake in Polyindole-Derived Microporous Carbon Materials, Environmental Science \& Technology 47 (2013) 5467-5473.

[17] D.M. Munoz, A.F. Portugal, A.E. Lozano, J.G. de la Campa, J. de Abajo, New liquid absorbents for the removal of $\mathrm{CO} 2$ from gas mixtures, Energy \& Environmental Science 2 (2009) 883-891.

[18] S. Kumar, S. Saxena, A comparative study of CO2 sorption properties for different oxides, Mater Renew Sustain Energy 3 (2014) 1-15. 
[19] G. Qi, Y. Wang, L. Estevez, X. Duan, N. Anako, A.-H.A. Park, W. Li, C.W. Jones, E.P. Giannelis, High efficiency nanocomposite sorbents for $\mathrm{CO} 2$ capture based on aminefunctionalized mesoporous capsules, Energy \& Environmental Science 4 (2011) 444-452.
[20] S. Zulfiqar, F. Karadas, J. Park, E. Deniz, G.D. Stucky, Y. Jung, M. Atilhan, C.T. Yavuz, Amidoximes: promising candidates for CO2 capture, Energy \& Environmental Science 4 (2011) 4528-4531.

[21] B. Jiang, V. Kish, D.J. Fauth, M.L. Gray, H.W. Pennline, B. Li, Performance of aminemultilayered solid sorbents for $\mathrm{CO} 2$ removal: Effect of fabrication variables, International Journal of Greenhouse Gas Control 5 (2011) 1170-1175.

[22] Y. Labreche, R.P. Lively, F. Rezaei, G. Chen, C.W. Jones, W.J. Koros, Post-spinning infusion of poly(ethyleneimine) into polymer/silica hollow fiber sorbents for carbon dioxide capture, Chemical Engineering Journal 221 (2013) 166-175.

[23] A. Samanta, A. Zhao, G.K.H. Shimizu, P. Sarkar, R. Gupta, Post-Combustion CO2 Capture Using Solid Sorbents: A Review, Industrial \& Engineering Chemistry Research 51 (2012) 14381463.

[24] M. Alfe, P. Ammendola, V. Gargiulo, F. Raganati, R. Chirone, Magnetite loaded carbon fine particles as low-cost $\mathrm{CO} 2$ adsorbent in a sound assisted fluidized bed, Proceedings of the Combustion Institute 35 (2015) 2801-2809.

[25] Y. Zhao, H. Ding, Q. Zhong, Preparation and characterization of aminated graphite oxide for CO2 capture, Applied Surface Science 258 (2012) 4301-4307.

[26] A.K. Mishra, S. Ramaprabhu, Magnetite decorated graphite nanoplatelets as cost effective CO2 adsorbent, Journal of Materials Chemistry 21 (2011) 7467-7471.

[27] K.-Y.A. Lin, A.-H.A. Park, Effects of Bonding Types and Functional Groups on CO2 Capture using Novel Multiphase Systems of Liquid-like Nanoparticle Organic Hybrid Materials, Environmental Science \& Technology 45 (2011) 6633-6639.

[28] A. Goeppert, M. Czaun, R.B. May, G.K.S. Prakash, G.A. Olah, S.R. Narayanan, Carbon Dioxide Capture from the Air Using a Polyamine Based Regenerable Solid Adsorbent, Journal of the American Chemical Society 133 (2011) 20164-20167.

[29] Z. Liu, Z. Du, W. Zou, H. Li, J. Mi, C. Zhang, Easily collected nano-absorbents for carbon dioxide capture, Chemical Engineering Journal 223 (2013) 915-920.

[30] W. Li, C.H. Hinton, S.S. Lee, J. Wu, J.D. Fortner, Surface engineering superparamagnetic nanoparticles for aqueous applications: design and characterization of tailored organic bilayers, Environmental Science: Nano 3 (2016) 85-93.

[31] L. Wenlu, L. Seung Soo, W. Jiewei, H.H. Carl, D.F. John, Shape and size controlled synthesis of uniform iron oxide nanocrystals through new non-hydrolytic routes, Nanotechnology 27 (2016) 324002.

[32] P. Tamilarasan, S. Ramaprabhu, Polyaniline-magnetite nanocapsules based nanocomposite for carbon dioxide adsorption, International Journal of Greenhouse Gas Control 10 (2012) 486493.

[33] Z. Hao, Q. Zhu, Z. Jiang, H. Li, Fluidization characteristics of aerogel Co/Al2O3 catalyst in a magnetic fluidized bed and its application to $\mathrm{CH} 4-\mathrm{CO} 2$ reforming, Powder Technology 183 (2008) 46-52.

[34] S. Brunauer, P.H. Emmett, E. Teller, Adsorption of Gases in Multimolecular Layers, Journal of the American Chemical Society 60 (1938) 309-319.

[35] B.D. Hall, D. Zanchet, D. Ugarte, Estimating nanoparticle size from diffraction measurements, Journal of Applied Crystallography 33 (2000) 1335-1341. 
[36] P. Scherrer, Bestimmung der grösse und der inneren struktur von kolloidteilchen mittels röntgensrahlen [Determination of the size and internal structure of colloidal particles using Xrays] Nachr Ges Wiss Goettingen Math. Phys. 1918 (1918) 98-100. [37] F. Wang, P. Liu, T. Nie, H. Wei, Z. Cui, Characterization of a Polyamine Microsphere and Its Adsorption for Protein, International Journal of Molecular Sciences 14 (2013) 17-29.

[38] J. Wu, D.G. Goodwin, K. Peter, D. Benoit, W. Li, D.H. Fairbrother, J.D. Fortner, PhotoOxidation of Hydrogenated Fullerene (Fullerane) in Water, Environmental Science \& Technology Letters 1 (2014) 490-494.

[39] J. Wu, L.B. Alemany, W. Li, L. Petrie, C. Welker, J.D. Fortner, Reduction of Hydroxylated Fullerene (Fullerol) in Water by Zinc: Reaction and Hemiketal Product Characterization, Environmental Science \& Technology 48 (2014) 7384-7392.

[40] J. Dong, Y. Ozaki, K. Nakashima, Infrared, Raman, and Near-Infrared Spectroscopic Evidence for the Coexistence of Various Hydrogen-Bond Forms in Poly(acrylic acid), Macromolecules 30 (1997) 1111-1117.

[41] K. Itano, J. Choi, M.F. Rubner, Mechanism of the pH-Induced Discontinuous Swelling/Deswelling Transitions of Poly(allylamine hydrochloride)-Containing Polyelectrolyte Multilayer Films, Macromolecules 38 (2005) 3450-3460.

[42] K. Shameli, M. Bin Ahmad, S.D. Jazayeri, S. Sedaghat, P. Shabanzadeh, H. Jahangirian, M. Mahdavi, Y. Abdollahi, Synthesis and Characterization of Polyethylene Glycol Mediated Silver Nanoparticles by the Green Method, International Journal of Molecular Sciences 13 (2012) 6639-6650.

[43] N. Su, H.B. Li, H.M. Zheng, S.P. Yi, X.H. Liu, Synthesis and characterization of poly(sodium-p-styrenesulfonate)/modified $\mathrm{SiO} 2$ spherical brushes, Express Polym. Lett. 6 (2012) 680-686.

[44] H. Liu, B. Zhang, H. Shi, Y. Tang, K. Jiao, X. Fu, Hydrothermal synthesis of monodisperse $\mathrm{Ag} 2 \mathrm{Se}$ nanoparticles in the presence of PVP and KI and their application as oligonucleotide labels, Journal of Materials Chemistry 18 (2008) 2573-2580.

[45] R. Bryaskova, D. Pencheva, S. Nikolov, T. Kantardjiev, Synthesis and comparative study on the antimicrobial activity of hybrid materials based on silver nanoparticles (AgNps) stabilized by polyvinylpyrrolidone (PVP), Journal of Chemical Biology 4 (2011) 185.

[46] J. Zhao, F. Simeon, Y. Wang, G. Luo, T.A. Hatton, Polyethylenimine-impregnated siliceous mesocellular foam particles as high capacity CO2 adsorbents, RSC Advances 2 (2012) 65096519.

[47] A. Sayari, Y. Belmabkhout, R. Serna-Guerrero, Flue gas treatment via CO2 adsorption, Chemical Engineering Journal 171 (2011) 760-774.

[48] A.D. Ebner, M.L. Gray, N.G. Chisholm, Q.T. Black, D.D. Mumford, M.A. Nicholson, J.A. Ritter, Suitability of a Solid Amine Sorbent for CO2 Capture by Pressure Swing Adsorption, Industrial \& Engineering Chemistry Research 50 (2011) 5634-5641. 

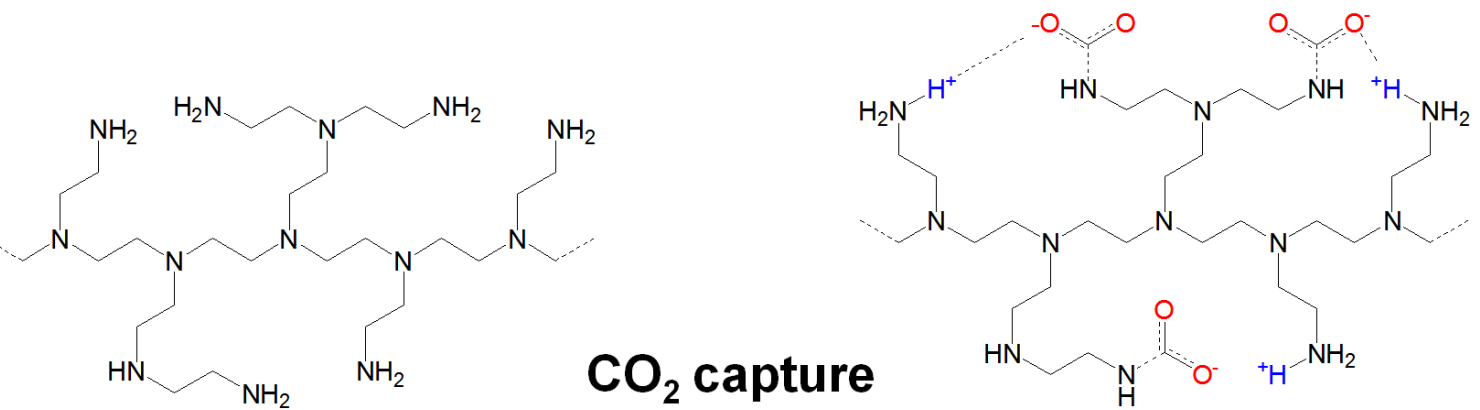